\title{
The Physiology and Maintenance of Respiration: A Narrative Review
}

Lynn R. Webster · Suzanne Karan

Received: August 27, 2020 / Accepted: September 26, 2020 / Published online: October 6, 2020

(C) The Author(s) 2020

\begin{abstract}
Chronic pain is one of the most common reasons adults seek medical care and is often managed with opioid analgesics; however, opioids may cause respiratory depression by suppressing various components of respiration. Respiration is the physiological process that facilitates gas exchange and is mediated through the proper function of and communication among central neural control (respiratory drive), sensory input systems, the lungs, and the muscles involved in respiration. Normal respiratory function can be dampened with the use of central nervous system (CNS) depressants and/or underlying health conditions. Patients with chronic pain are often exposed to CNS depressants other than opioids,
\end{abstract}

L. R. Webster ( $\square)$

PRA Health Sciences, Salt Lake City, UT, USA

e-mail: WebsterLynn@prahs.com

S. Karan

University of Rochester Medical Center, Rochester,

NY, USA including benzodiazepines, barbiturates, nonbenzodiazepine sedative-hypnotics, and ethanol, which can function synergistically with opioids to increase the risk of respiratory depression. Some patients may also have underlying health issues, such as obstructive sleep apnea, that can be exacerbated with the use of opioids and other CNS depressants and further contribute to respiratory depression. Clinicians should have a thorough understanding of respiration, recognize how various CNS depressants suppress it, and take necessary steps to mitigate the risk of opioid-induced respiratory depression by collaborating with a multidisciplinary team (i.e., sleep and pain specialists), choosing appropriate medications, and educating patients on the proper use and storage of opioids.

Keywords: Breathing; Central nervous system depressants; Chronic pain; Opioids; Respiratory depression; Respiratory system; Ventilation 


\section{Key Summary Points}

Patients with chronic pain are often exposed to one or more central nervous system depressants (e.g., opioids, benzodiazepines, barbiturates, nonbenzodiazepine sedative-hypnotics, and ethanol) and may have underlying health conditions (e.g., obstructive sleep apnea) that impact respiration.

Respiration is facilitated by the communication of central neural control (respiratory drive), sensory input systems, respiratory muscles, and the lungs, which enable gas exchange $\left(\mathrm{O}_{2}\right.$ and $\left.\mathrm{CO}_{2}\right)$ between the alveoli and the blood.

Central nervous system depressants and underlying conditions can suppress one or more steps in respiration, thereby leading to respiratory depression.

Clinicians should have a thorough understanding of the physiology behind respiration, take precautions when prescribing central nervous system depressants, collaborate with a multidisciplinary team (including sleep and pain specialists), and educate patients on the proper use and storage of medications to prevent the occurrence of respiratory depression.

\section{DIGITAL FEATURES}

This article is published with digital features, including a summary slide, to facilitate understanding of the article. To view digital features for this article go to https://doi.org/10.6084/ m9.figshare.13008023.

\section{INTRODUCTION}

In the USA, chronic pain is one of the most frequent reasons adults seek medical attention
$[1,2]$. Results from the 2012 National Health Interview Survey showed that approximately 25.3 million adults in the USA experienced chronic pain [3]. Chronic pain is often managed with opioid analgesic medication $[2,4,5]$. Opioid analgesics are frequently diverted and used improperly, which has contributed to a national crisis of opioid overdose deaths $[5,6]$. Opioids act primarily on mu-opioid receptors in the central nervous system (CNS), including receptors located on neuronal centers that play a key role in regulating respiratory drive, the ability of neuronal respiratory centers to control ventilation [7]. Failure in one or more steps of respiratory drive leads to respiratory depression, the medical outcome that occurs when inadequate ventilation of the lungs decreases the rate of gas exchange [8]. Opioid-induced respiratory depression is the leading cause of death in patients who overdose with or abuse opioids $[4,5,9,10]$.

Patients with chronic pain may not be treated only with opioid analgesics but may also be exposed to other CNS depressants, or a combination of them, including benzodiazepines, barbiturates, nonbenzodiazepine sedative-hypnotics (also known as $\mathrm{Z}$ drugs), and ethanol. Along with opioids, each of these agents can cause respiratory depression. Therefore, it is important that clinicians understand the mechanisms behind respiration and the impact of suppressant agents on respiratory drive and patency.

The purpose of this review is to provide an overview of the physiology behind respiration, maintenance of ventilation, and the various CNS depressant agents that affect normal physiological responses. The information presented here can be used as an educational resource for clinicians to improve decisionmaking and medication selection regarding potential impacts on respiratory function.

This article is based on previously conducted studies and does not contain any studies with human participants or animals performed by any of the authors. 


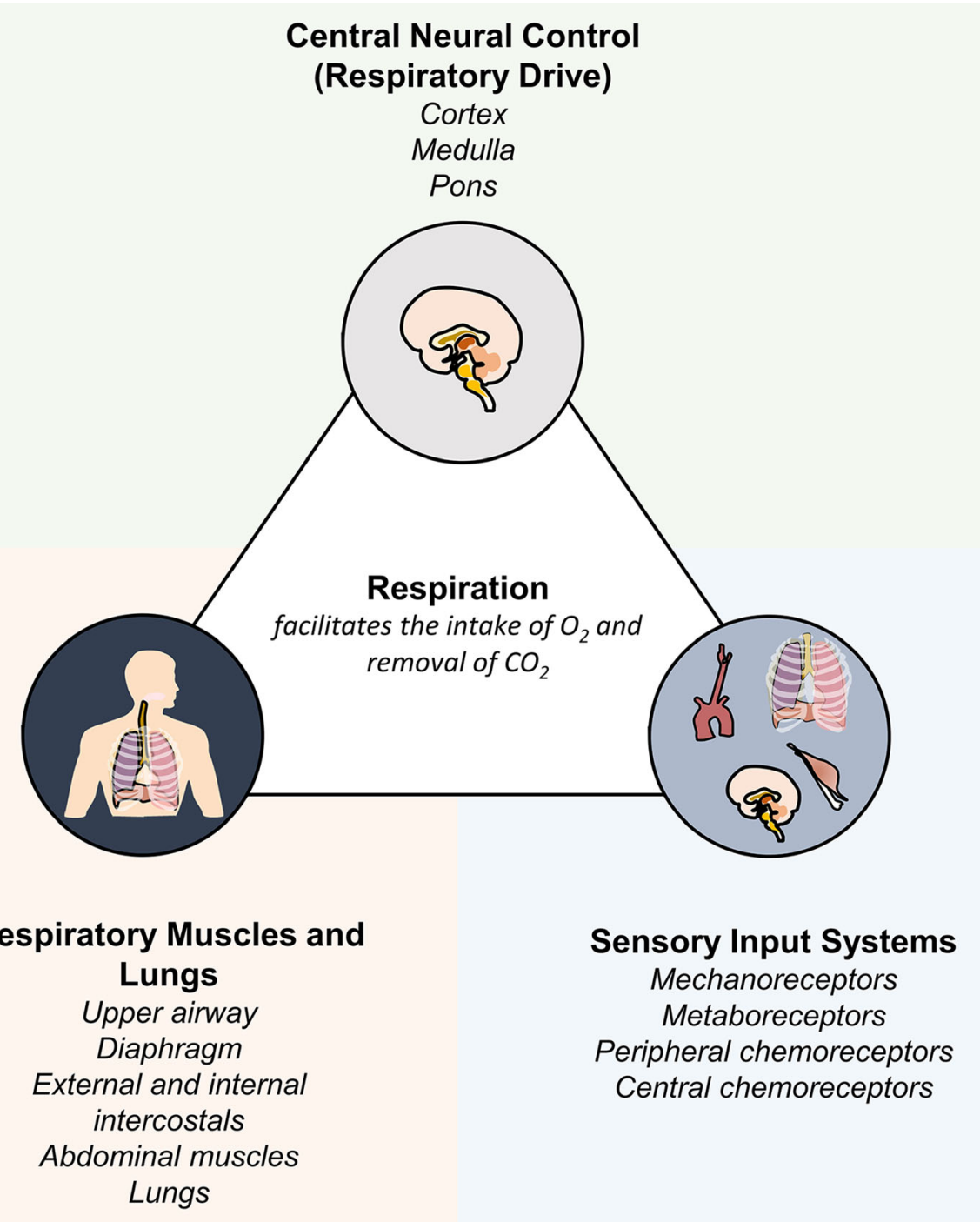

Fig. 1 Three primary components that facilitate respiration. Respiration is mediated by central neural control through the cortex and the respiratory center in the brain (the medulla and pons); sensory input systems, including mechanoreceptors, metaboreceptors, and peripheral and central chemoreceptors located in the CNS, carotid arteries, and muscles; and respiratory muscles, which

\section{DISCUSSION}

\section{Respiration}

Respiration encompasses the processes that facilitate gas exchange on a cellular level, which include the upper airway, diaphragm, external and internal intercostals, and abdominal muscles and the lungs. Each of these systems coordinates with one another to control the diffusion of essential chemicals and gases between the circulatory system and the environment. CNS central nervous system

involves the intake of $\mathrm{O}_{2}$ and the removal of $\mathrm{CO}_{2}$ [11]. Respiration involves the synchronization of various components, including central neural control (respiratory drive), sensory input systems, respiratory muscles, and lungs (Fig. 1) [11-13]. Central neural control 
and sensory input systems coordinate the timing and rate of ventilation and air volume intake, which is signaled to the respiratory muscles and lungs for the mechanical exchange of inspired gases (i.e., air) [11, 14].

\section{Central Neural Control}

The respiratory center in the brain is controlled by the pons and medulla (Fig. 2a) [15]. These neural control centers work collectively to regulate inspiration and exhalation [15]. The cerebral cortex influences the respiratory centers of the brain to control conscious (i.e., breath holding) or unconscious (i.e., speech, singing, coughing) respiration [16-18].

\section{Medullary Groups}

The dorsal medulla is responsible for inhalation and airway defense, while the ventral medulla is responsible for exhalation $[11,19,20]$. The strength of the signal from the dorsal medulla can influence breathing, whereby increased impulse frequency results in stronger muscle contractions and deeper breathing, and decreased frequency results in passive expiration [21]. The dorsal medulla communicates with the ventral medulla by integrating input from central and peripheral receptors prior to relaying information to respiratory muscles to generate respiratory rhythm [21]. The pre-Bötzinger complex is a group of neurons located between the ventral respiratory group and the Bötzinger complex in the brainstem that also functions to control inspiration [7]. The preBötzinger complex interacts with respiratory centers to ensure a smooth transition between different breathing phases, while also preventing the activation of opposing muscle groups [7]. The principal neurotransmitters involved in modulating the generation and transmission of respiratory rhythm are glutamate, gammaaminobutyric acid (GABA), and glycine [22].

\section{Pontine Grouping}

The pontine grouping allows for modulation of the intensity and frequency of medullary signals to control breathing patterns while promoting a smooth transition between inspiration and expiration $[21,23]$. More specifically, the pneumotaxic center in the upper portion of the pons coordinates the speed of breathing, sends inhibitory impulses to the respiratory center, and is involved in the fine-tuning of respiratory rate [24]. The apneustic center in the lower portion of the pons also coordinates the speed of breathing but can be overridden by the pneumotaxic center to end inhalation; this region is mostly responsible for sending stimulatory impulses to the inspiratory area (prolonging inhalation) [24]. Suprapontine areas also contribute to respiration by responding to changes in internal or external environmental conditions such as exercise, hypoxia, hypercapnia, and thermal changes, as well as other processes like swallowing and coughing $[18,25]$. These neuronal processes are modulated by incoming sensory input systems [26].

\section{Sensory Input Systems}

Sensory input systems consist of mechanoreceptors, metaboreceptors, and peripheral and central chemoreceptors that coordinate with other components of the respiratory response system to control breathing (Fig. 2b) $[11,27,28]$.

\section{Mechanoreceptors and Metaboreceptors}

Mechanoreceptors are located throughout the respiratory tract in the airways, trachea, lungs, and pulmonary vessels. They provide sensory information to the respiratory center of the brain regarding the mechanical status of the lungs and chest, including the rate of breathing, lung space, and irritation triggers $[11,27]$. Pulmonary stretch receptors can be classified as slowly or rapidly adapting, where slowly adapting receptors are activated during inflation of the lungs and play a critical role in the Hering-Breuer reflex (termination of inspiration and prolongation of expiration), and rapidly adapting receptors initiate defensive respiratory reflexes in response to irritants $[27,29]$. Bronchopulmonary C-fiber receptors also play a role in initiating defensive respiratory reflexes in response to inhaled irritants or rapid changes in lung volume [27]. Other 


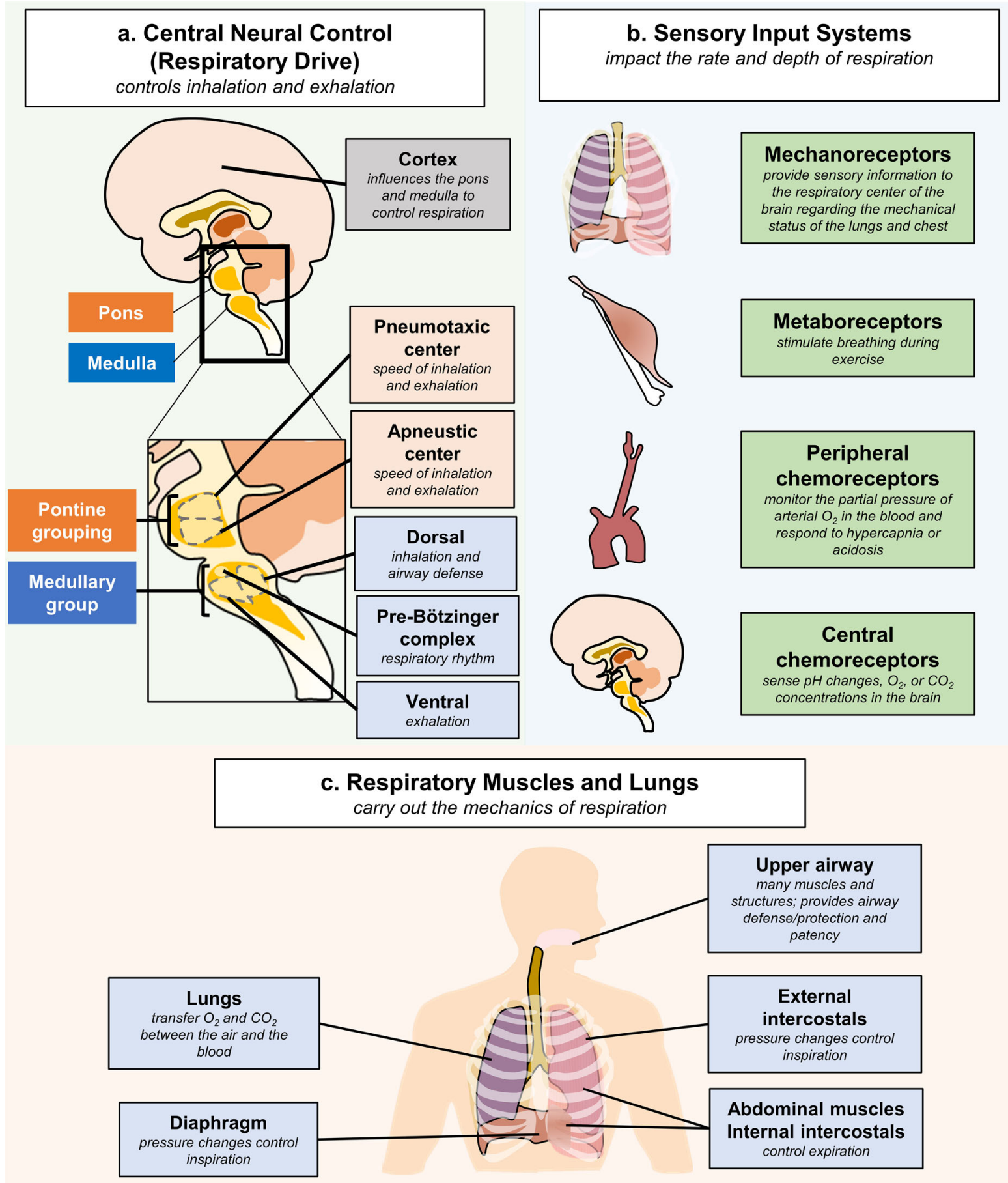

Fig. 2 Control of respiration. a The respiratory center in the brain controls various components of respiratory drive, including inhalation, airway defense, exhalation, and breathing patterns. b The sensory input systems are composed of mechanoreceptors, metaboreceptors, and peripheral and central chemoreceptors that sense chemical changes and influence various components of respiration, such as breathing, lung space, and irritation triggers. c Neuronal processes and sensory input systems are communicated to the respiratory muscles and lungs to control the mechanical aspects of respiration 
receptors called metaboreceptors are found in the skeletal muscle and are activated by metabolic byproducts to stimulate breathing during exercise [30].

\section{Peripheral Chemoreceptors}

Peripheral chemoreceptors consist of fast-acting carotid and aortic bodies that monitor the partial pressure of arterial $\mathrm{O}_{2}$ in the blood and respond to hypercapnia or acidosis [28, 31]. Carotid body chemoreceptors are located at the bifurcation of the common carotid arteries and are responsible for the majority of the peripheral control of ventilation [28, 31, 32]. Carotid bodies are also able to sense arterial gas concentrations and $\mathrm{pH}$, which initiates a rapid response (within 1-3 s) by stimulating ventilation via communication with medullary response neurons [24, 28]. Aortic bodies are located near the arch of the aorta and play a large role in regulating circulation while also responding to changes in gas concentrations $[24,28]$.

\section{Central Chemoreceptors}

Central chemoreceptors are located within the ventral surface of the medulla and retrotrapezoid nucleus and are responsible for sensing $\mathrm{pH}, \mathrm{O}_{2}$, or $\mathrm{CO}_{2}$ concentration changes in the brain and cerebrospinal fluid $[7,11,26,32,33]$. An acidic environment (increased hydrogen ions) in the brain triggers the respiratory center to initiate contraction of the diaphragm and intercostal muscles [26]. As a result, the rate and depth of respiration increase, allowing for more $\mathrm{CO}_{2}$ to be expelled and thereby reducing $\mathrm{CO}_{2}$ levels and hydrogen ions in the blood [26]. Conversely, low levels of $\mathrm{CO}_{2}$ in the blood cause low levels of hydrogen ions in the brain, ultimately leading to a decrease in the rate and depth of ventilation and the slowing of breathing [26]. Taken together, these processes function to normalize $\mathrm{pH}$ [31]. Of all the sensory input systems, central chemoreceptors are thought to have primary control over respiration, which is ultimately carried out by respiratory muscles and the lungs [11, 33].

\section{Respiratory Muscles and Lungs}

Information from neuronal and sensory input systems signals to the diaphragm and other respiratory muscles to control the mechanical aspects of respiration (Figs. 2c, 3) [21, 34-37]. The upper airway is composed of many soft tissues, muscles, and bony structures that modulate patency for respiratory functions [38]. The upper airway can be influenced by cortical states, sensory input, drugs, and passive changes in lung volume, which ultimately functions to modulate reflex activity and provide defense/ protection and maintenance of the airway [32, 38, 39]. The depth of inspiration during breathing is based on the level of activity of the respiratory center in the brain and subsequent stimulation of motor neurons [40]. With more stimulation, an increased number of motor units are excited, leading to respiratory muscles contracting with greater force [21].

Contraction and relaxation of the diaphragm and external intercostals are responsible for most of the pressure changes that result in inspiration [26]. Accessory muscles of inspiration include the scaleni, sternocleidomastoid, and anterior serrati; however, they do not play a role in passive breathing [41]. The most important muscles for expiration are the abdominal muscles and internal intercostals, which contract and compress the abdominal organs pushing them up into the diaphragm, raising pleural pressure and alveolar pressure, and driving air out of the lungs [41]. Respiratory exchange surfaces in the lungs transfer $\mathrm{O}_{2}$ and $\mathrm{CO}_{2}$ between the air and the blood [28]. $\mathrm{O}_{2}$ crosses the alveoli in the lungs to the blood and is transported to tissues, while $\mathrm{CO}_{2}$ is removed from the blood and transferred to the alveoli prior to exchange back to the environment [42]. The combination of these processes results in an average resting respiratory rate of approximately 12 breaths per minute in a healthy adult $[11,41]$. Minute ventilation is the product of respiratory rate and tidal volume, with a normal tidal volume being approximately $7 \mathrm{~mL} / \mathrm{kg}$ of ideal body weight (approximately $500 \mathrm{~mL}$ in an average healthy adult male and $400 \mathrm{~mL}$ in a healthy adult female) $[41,43]$. Assessment of this and other components of respiration can 


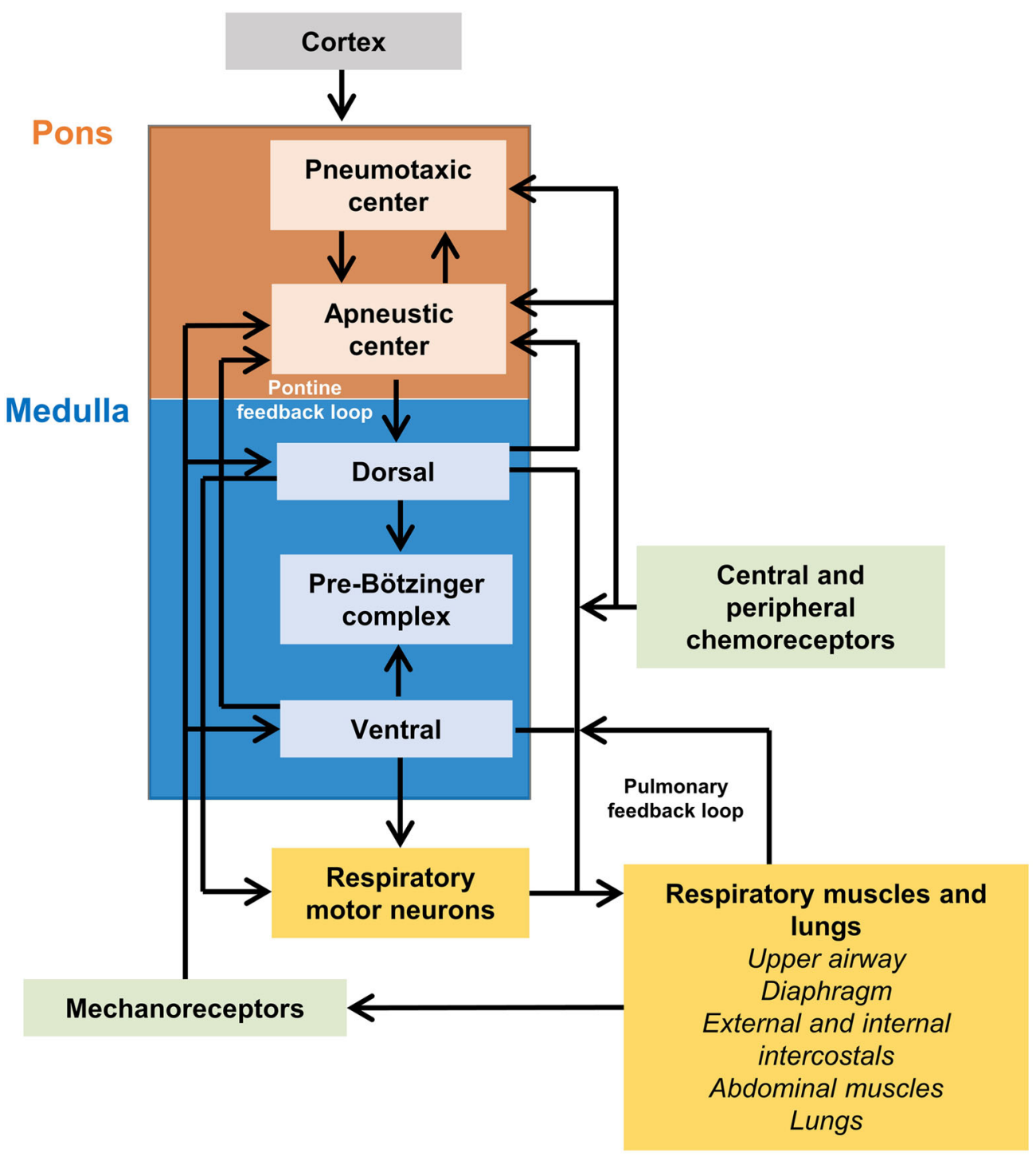

Fig. 3 Respiration is mediated by communication among central neural control, sensory input systems, respiratory muscles, and the lungs. Neuronal and sensory input

provide insight into a patient's overall respiratory health.

In healthy adults, the rise in ventilation as the partial pressure of $\mathrm{CO}_{2}\left(\mathrm{PaCO}_{2}\right)$ increases can be observed in a linear fashion (Fig. 4) $[28,44-46]$. In the setting of hypoxia, the body is more sensitive to changes in $\mathrm{PaCO}_{2}$, as both central and peripheral chemoreceptors cause an additive increase in respiratory drive [46]. During sedation, metabolism and minute ventilation are both decreased [28]. CNS depressants systems coordinate with respiratory muscles and the lungs to control the mechanical aspects of respiration

that cause respiratory depression, such as opioids, can further dampen the $\mathrm{CO}_{2}$ response curve, causing a right-shift (decreased threshold) [46]. The further the shift to the right, the more likely respiratory depression is to occur. Opioids and other CNS depressants can also relax airway muscles, decrease upper airway patency, disengage protective arousal mechanisms, and cause obstructed breathing, which further reduces effective ventilation in the setting of decreased respiratory drive [47-51]. 


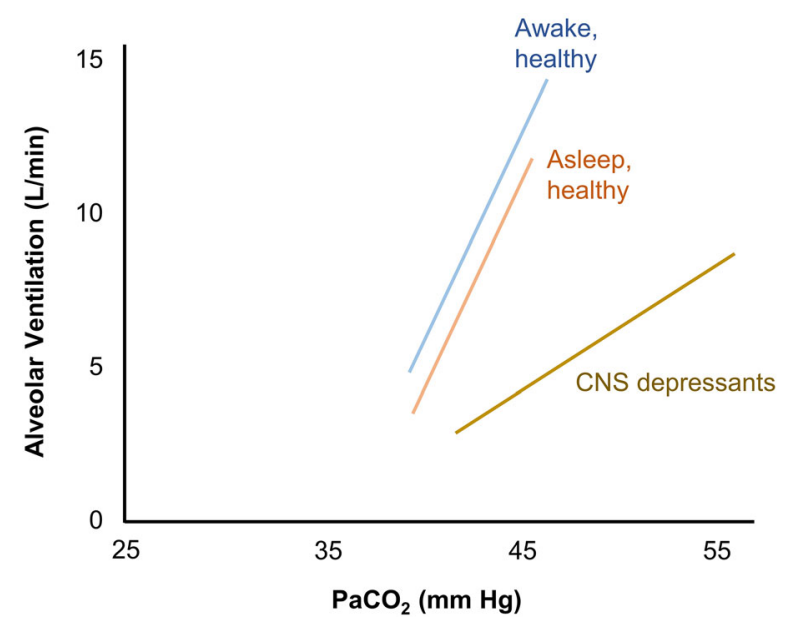

Fig. $4 \mathrm{CO}_{2}$ response curve during normal respiration, sedation, and CNS depressant exposure. This figure was modified from Benner et al. [46] under the terms of the Creative Commons Attribution 4.0 International License (https://creativecommons.org/licenses/by/4.0/). The $\mathrm{CO}_{2}$ response curve functions as a graphical depiction of the linear relationship between increases in $\mathrm{PaCO}_{2}$ and alveolar ventilation. These response curves vary for each person within a population, with roughly a 1 to $4 \mathrm{~L} / \mathrm{min}$ increase in minute ventilation for each $1 \mathrm{~mm} \mathrm{Hg}$ increase in $\mathrm{PaCO}_{2}$. As the $\mathrm{CO}_{2}$ response is dampened, a right-shift occurs. CNS central nervous system, $\mathrm{PaCO}_{2}$ partial pressure $\mathrm{CO}_{2}$

\section{Clinical Manifestations of Respiratory Depression}

The clinical manifestations of respiratory depression and failure exist on a continuum and may vary depending on the reason(s) for onset (i.e., disease and/or drug-induced) and the severity of hypoventilation, onset of hypercapnia, and degree of respiratory acidosis [52]. Typically, during the early stages of respiratory depression, patients are asymptomatic or may experience anxiousness and dyspnea upon exertion [52]. As the degree of respiratory depression progresses, dyspnea at rest, disturbed sleep, and daytime hypersomnolence can occur. With continued progression, cyanosis, delirium, somnolence, asterixis, seizures, and papilledema may occur and be followed by respiratory failure that requires ventilatory support or death [52]. Progression to respiratory failure may not follow this continuum for all patients and can be exacerbated with the use of CNS depressant agents or from the presence of underlying conditions that impact one or more steps in respiration.

\section{Respiratory Depressants}

Pharmaceutical and recreational agents classified as CNS depressants can suppress one or more steps in respiration and patency. Common agents that are known as inducers of respiratory depression are benzodiazepines, barbiturates, Z drugs, opioids, and ethanol [53]. These different classes suppress respiration by affecting various components of the respiratory system (Table 1; Fig. 5) [18, 47-51, 54-62].

\section{Barbiturates}

Barbiturates are a class of sedative-hypnotic drugs used for a variety of purposes [54]. Phenobarbital and primidone are often used in the treatment of seizures, amobarbital is used as an investigative agent for the neurological assessment of cerebral hemispheres, and secobarbital is used for insomnia [54, 63]. Barbiturates generally act on $\mathrm{GABA}_{\mathrm{A}}$ receptors by increasing the amount of time the chloride ion channel is opened, which increases GABA receptor affinity (Table 1) [54]. These drugs can also act to increase chloride influx in the absence of GABA, which further depresses the CNS [54]. Ultimately, these processes can lead to suppression of upper airway patency and central neuronal control of ventilation [55].

\section{Benzodiazepines}

Benzodiazepines are widely prescribed in general practice for their anxiolytic, sedative, anticonvulsant, and muscle relaxant effects [64]. These agents bind directly to various $\mathrm{GABA}_{\mathrm{A}}$ receptor subtypes and increase the inhibitory effects of endogenous GABA (Table 1) [18, 56]. Benzodiazepines can depress central respiratory drive, chemoreceptor responsiveness to hypercapnia, peripheral chemoreceptors, and inspiratory and expiratory respiratory muscle strength in a dosedependent manner, thus reducing respiration $[47,57,58]$. Benzodiazepines can also cause upper airway obstruction via relaxation of the 
Table 1 Effects of CNS depressants on respiration

\begin{tabular}{lll}
\hline Agent & Mechanism of action & Effects on respiration \\
\hline
\end{tabular}

\section{Barbiturates}

Amobarbital

Agonism at $\mathrm{GABA}_{\mathrm{A}}$ receptors; inhibition of

Pentobarbital

$$
\text { excitatory neurotransmission }
$$

Phenobarbital

Primidone

Secobarbital

Methohexital

\section{Benzodiazepines}

Alprazolam

Clonazepam

Diazepam

Agonism at several $\mathrm{GABA}_{\mathrm{A}}$ receptor subtypes in the peripheral nervous system or in peripheral tissues

Lorazepam

Nonbenzodiazepine sedative-hypnotics (also known as $\mathbf{Z}$ drugs)

Eszopiclone Agonism at one type of $\mathrm{GABA}_{\mathrm{A}}$ receptor

Zolpidem

Zaleplon

Zopiclone

\section{Opioids}

Full mu-opioid receptor agonists

Codeine

Fentanyl

Hydrocodone

Full agonism at mu-opioid receptors in the CNS and peripheral opioid receptors; agonism at kappa-opioid receptors

Hydromorphone

Morphine

Dihydrocodeine

Heroin

Oxymorphone

Oxycodone
Suppresses central neural control and central and peripheral mechanisms; obstructs the upper airway

Depresses central respiratory drive, chemoreceptor responsiveness to hypercapnia, peripheral chemoreceptors, and inspiratory and expiratory respiratory muscle strength; obstructs the upper airway

Depresses central respiratory drive; decreases respiratory muscle strength; may depress upper airway resistance

Interacts with neurons in the pons and medulla, including the pre-Bötzinger complex, and suppresses central and peripheral chemoreceptors; blunts the normal responses to hypoxemia and hypercapnia; reduces upper airway patency 
Table 1 continued

\begin{tabular}{|c|c|c|}
\hline Agent & Mechanism of action & Effects on respiration \\
\hline \multicolumn{3}{|l|}{ Atypical } \\
\hline Buprenorphine & $\begin{array}{l}\text { Partial mu-opioid receptor agonist; agonist at } \\
\text { ORL-1; antagonist at the kappa-opioid and } \\
\text { delta-opioid receptors }\end{array}$ & $\begin{array}{l}\text { Similar to full mu-opioid receptor agonist opioids, } \\
\text { but to a lesser extent }\end{array}$ \\
\hline Tapentadol & $\begin{array}{l}\text { Full mu-opioid receptor agonist; norepinephrine } \\
\text { reuptake inhibitor }\end{array}$ & \\
\hline Tramadol & $\begin{array}{l}\text { Full mu-opioid receptor agonist; norepinephrine } \\
\text { and serotonin reuptake inhibitor }\end{array}$ & \\
\hline \multicolumn{3}{|l|}{ Other } \\
\hline Ethanol & $\begin{array}{l}\text { Binds strongly to GABA receptors to decrease } \\
\text { excitation }\end{array}$ & $\begin{array}{l}\text { Suppresses neurotransmission pathways; decreases } \\
\text { the response to increased } \mathrm{CO}_{2} \text { and decreased } \\
\text { oxygenation; impacts airway patency }\end{array}$ \\
\hline Diphenhydramine & $\mathrm{H}_{1}$-receptor antagonist & $\begin{array}{l}\text { Augments the interaction between hypoxic and } \\
\text { hypercapnic ventilatory drive }\end{array}$ \\
\hline
\end{tabular}

$C N S$ central nervous system, $G A B A_{A}$ gamma-aminobutyric acid ${ }_{\mathrm{A}}, O R L-1$ opioid receptor-like 1

tongue and neck [47]. Dose-dependent effects on reducing resting ventilation and the ventilatory response to hypoxia and hypercapnia can occur [18]. As such, benzodiazepine use has been associated with an increased risk of respiratory depression, especially when used in combination with opioids and alcohol [58, 65].

\section{Z Drugs}

Nonbenzodiazepine hypnotics, such as zolpidem and zaleplon, are also referred to as $\mathrm{Z}$ drugs and are extremely useful in the treatment of insomnia owing to their quick onset and short duration [56]. Similarly to benzodiazepines, they too act at the $\mathrm{GABA}_{\mathrm{A}}$ receptor, but in a more specific manner (Table 1) [56]. A consequence of their greater specificity is less anxiolytic and anticonvulsant activity [56]. Similarly to benzodiazepines, these drugs may cause respiratory depression by suppressing central respiratory drive, decreasing respiratory muscle strength, and increasing upper airway resistance $[59,60]$. However, a recent clinical study found differential effects on the respiratory arousal threshold, with no reduction in upper airway muscle activity or alteration of airway collapsibility during sleep—instead, muscle activity increased during airway narrowing [66].

\section{Opioids}

Opioids are often prescribed for acute and chronic pain relief, as they provide analgesia by acting on mu-opioid receptors located throughout the CNS (Table 1; Fig. 6) $[47,50,51]$. Opioid-induced respiratory depression can occur through the suppression of respiratory drive by interacting with neurons in the pons and medulla, including the preBötzinger complex, or suppressing peripheral or central chemoreceptors, which impacts respiratory rhythm and blunts the normal response to hypoxemia and hypercapnia (Fig. 7) [47-51]. Opioids also suppress neural signals to the upper airway dilator muscles, thereby impacting upper airway patency [61].

Based on their agonistic activity at the muopioid receptor, the impact on respiratory drive and extent of respiratory depression varies among different opioids $[67,68]$. The risk of respiratory depression is greater with classic full mu-opioid receptor agonists, such as morphine, hydrocodone, and oxycodone, than it is with 


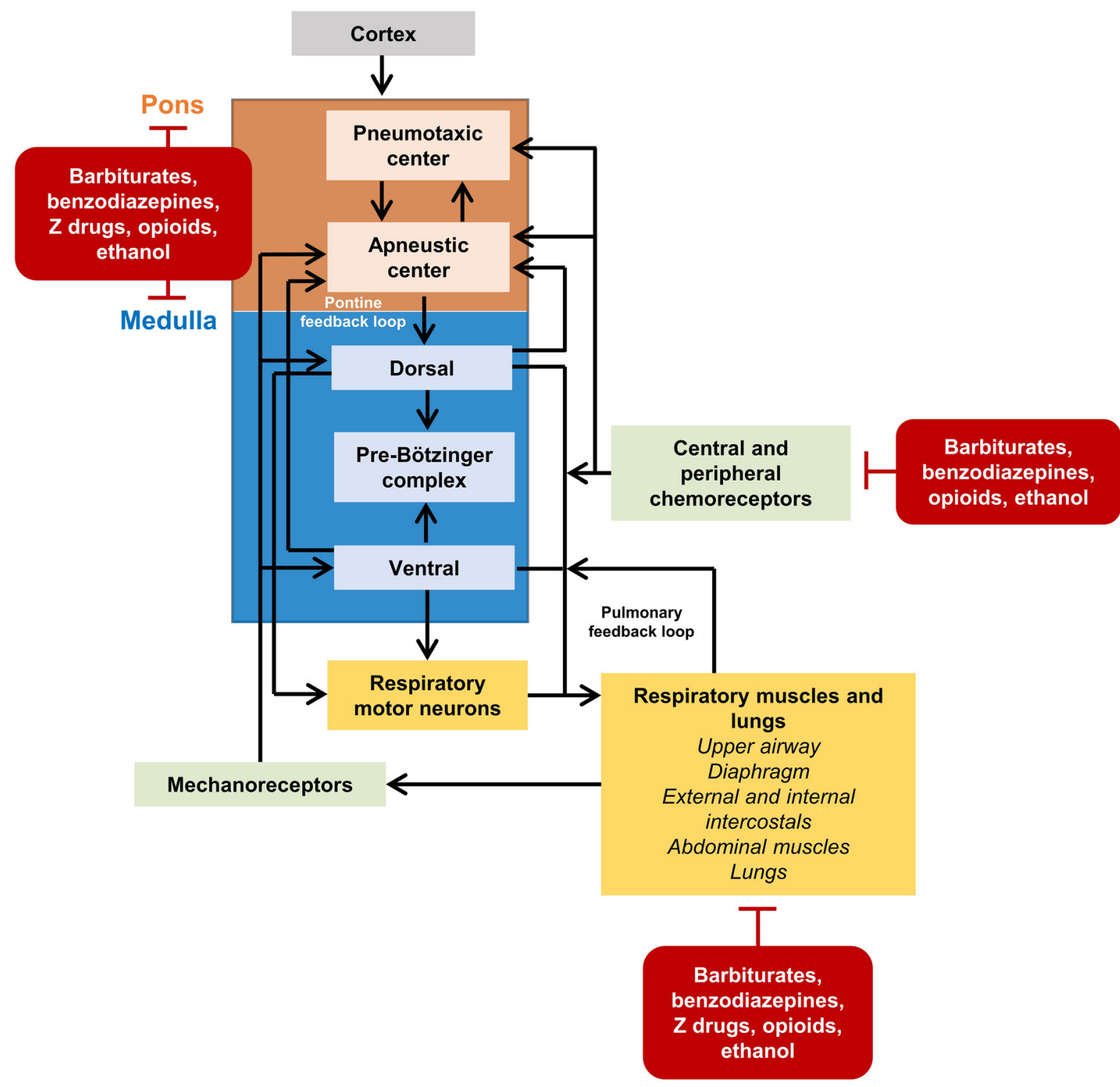

Fig. 5 Effect of CNS depressants on respiration. Pharmaceutical and recreational agents such as barbiturates, benzodiazepines, $\mathrm{Z}$ drugs, opioids, and ethanol can suppress multiple steps in respiration to cause respiratory depression

atypical opioids, such as tramadol, tapentadol, and buprenorphine, because these atypical opioids are mixed-mechanism drugs $[1,48,67,69-71]$. For example, in addition to being full mu-opioid receptor agonists, tramadol and tapentadol have been shown to activate descending pain inhibitory pathways through norepinephrine reuptake inhibition, with tramadol also acting as a serotonin reuptake inhibitor [72, 73]. Buprenorphine is a partial mu-opioid receptor agonist, an antagonist at the kappa- and delta-opioid receptors, and a full agonist at opioid receptor-like 1 [74]. Of the classic and atypical opioids, buprenorphine has unique partial agonism and signaling profiles at the mu-opioid receptor, which may result in a ceiling effect on respiratory depression but not on analgesia (Fig. 8) [67, 70, 75-79]. Mu-opioid receptors are coupled to inhibitory proteins that, upon activation, separate from one another to engage in a variety of intracellular signaling cascades that depress neural functions 


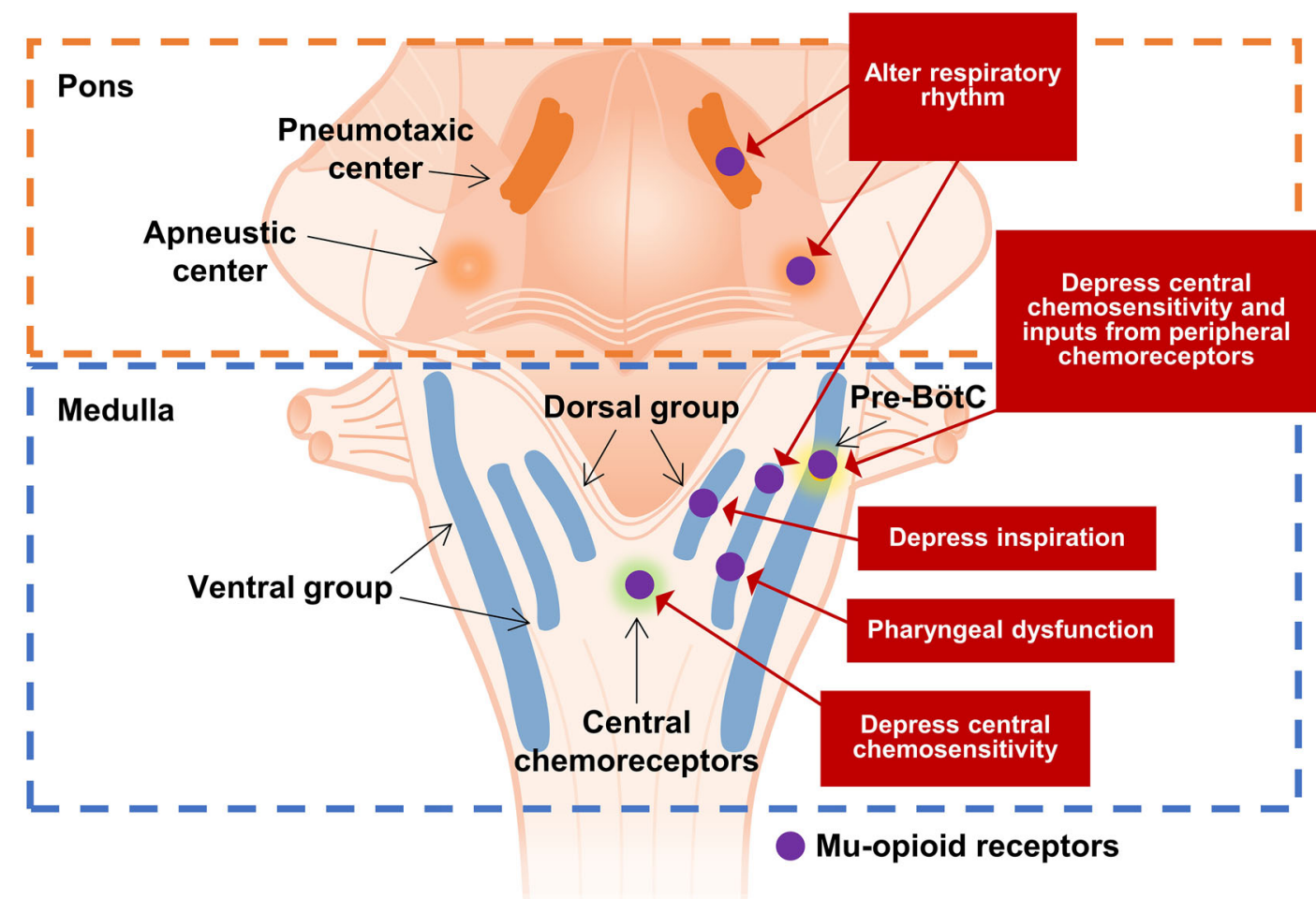

Fig. 6 Opioid effects on central neural control. Opioids interact with mu-opioid receptors located throughout the respiratory centers in the brainstem, which under certain

[79]. Full mu-opioid receptor agonists recruit (an adaptor protein) that is associated with signaling events that lead to poor outcomes such as respiratory depression, whereas the biased signaling mechanism elicited by buprenorphine limits $\beta$-arrestin recruitment, which may contribute to an enhanced safety profile [74].

\section{Other}

Alcohol is a widely used and abused recreational substance that contributes to approximately $15 \%$ of opioid overdose deaths [62, 80]. Alcohol is primarily metabolized in the liver by alcohol dehydrogenase to acetaldehyde, which increases CNS inhibition and decreases excitation through interactions with GABA receptors (Table 1) [62]. This can suppress central neuronal control and upper airway patency, thereby resulting in respiratory depression [62]. circumstances may suppress various components of respiratory drive. Pre-BötC pre-Bötzinger complex

Diphenhydramine may also impact respiratory drive (Table 1) [81]. In addition to its use in the relief of allergy symptoms, diphenhydramine is frequently used to treat pruritus and nausea in patients who have received neuraxial opioids and was found to augment the interaction between hypoxic and hypercapnic ventilatory drive in healthy patients [81]. However, additional research is needed to determine any additional effects of diphenhydramine on respiratory drive.

\section{Herbal Supplements}

Patients with chronic pain are likely to seek out herbal supplements for pain relief, which may be used in conjunction with prescription medications [82]. Some common supplements utilized for their analgesic properties, but that may also suppress the CNS, include kratom, 


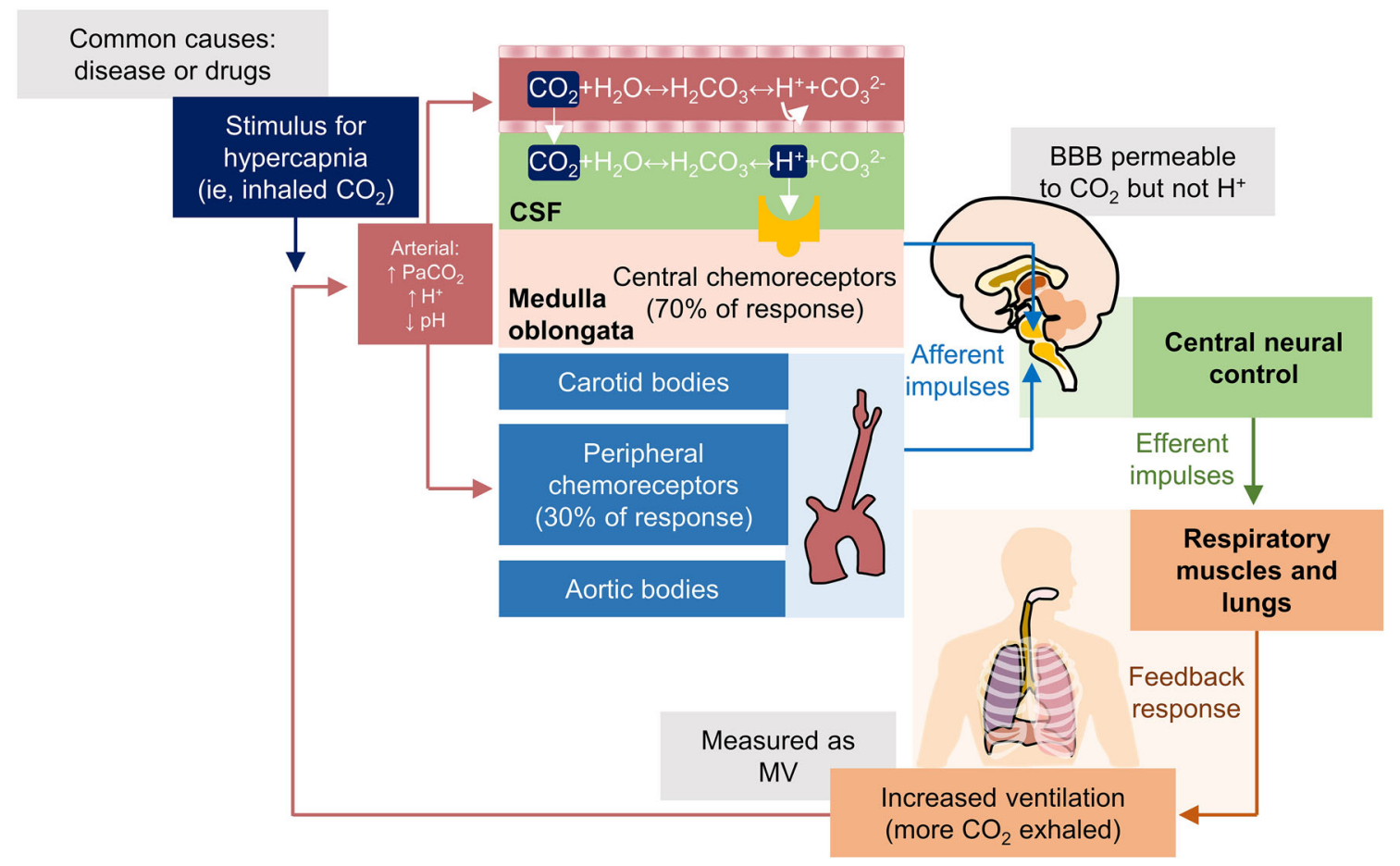

Fig. 7 Feedback response to hypercapnia. Hypercapnia results from a stimulus such as an inhaled gas mixture, a disease, or CNS depressants. Respiratory drive depends on the activity of central and peripheral chemoreceptors that respond to changes in $\mathrm{CO}_{2}$ and $\mathrm{pH}$ levels in the blood and CSF. A feedback loop among central and peripheral chemoreceptors, central neural control, and respiratory muscles and lungs allows for coordination of respiration to

synthetic cannabinoids, valerian root, and kava [82-86]. Although additional research is needed to determine the specific effects of these agents on respiratory drive, clinicians must provide proper education to patients with chronic pain regarding the risks associated with concomitant use of supplements with their current prescriptions.

\section{Concomitant Use}

When analgesic drugs from different classes are combined, the resulting effects are typically synergistic rather than merely additive [87]. Synergy between CNS depressants is more common when drugs acting primarily on GABA receptors (e.g., barbiturates, benzodiazepines, $Z$ drugs, ethanol) are combined with drugs acting on other receptor types (e.g., opioids) [87]. It normalize $\mathrm{CO}_{2}$ and $\mathrm{pH}$ levels. Measuring the ventilatory response to hypercapnia is a common research assessment that reflects the ability of central chemoreceptors to carry out a normal respiratory response. $B B B$ blood-brain barrier, $C N S$ central nervous system, $C S F$ cerebrospinal fluid, $\mathrm{MV}$ minute ventilation, $\mathrm{PaCO}_{2}$ partial pressure of carbon dioxide

is especially important to note that respiratory depression is a potentially fatal complication of opioid use and may be exacerbated by simultaneous ethanol intake [88]. One clinical trial showed that ethanol ingestion with concomitant oxycodone use resulted in clinically relevant ventilatory depression to a greater extent than when either agent was used alone [88]. The combination of an opioid, benzodiazepine, and the skeletal muscle relaxant carisoprodol is commonly referred to as the "Holy Trinity," and these medications behave synergistically to induce respiratory depression, which could collectively result in death $[89,90]$. Compared to treatment alone, the combination of opioids with benzodiazepines or alcohol has been shown to increase the risk of serious adverse respiratory events by $31 \%$ [91]. Thus, clinicians 


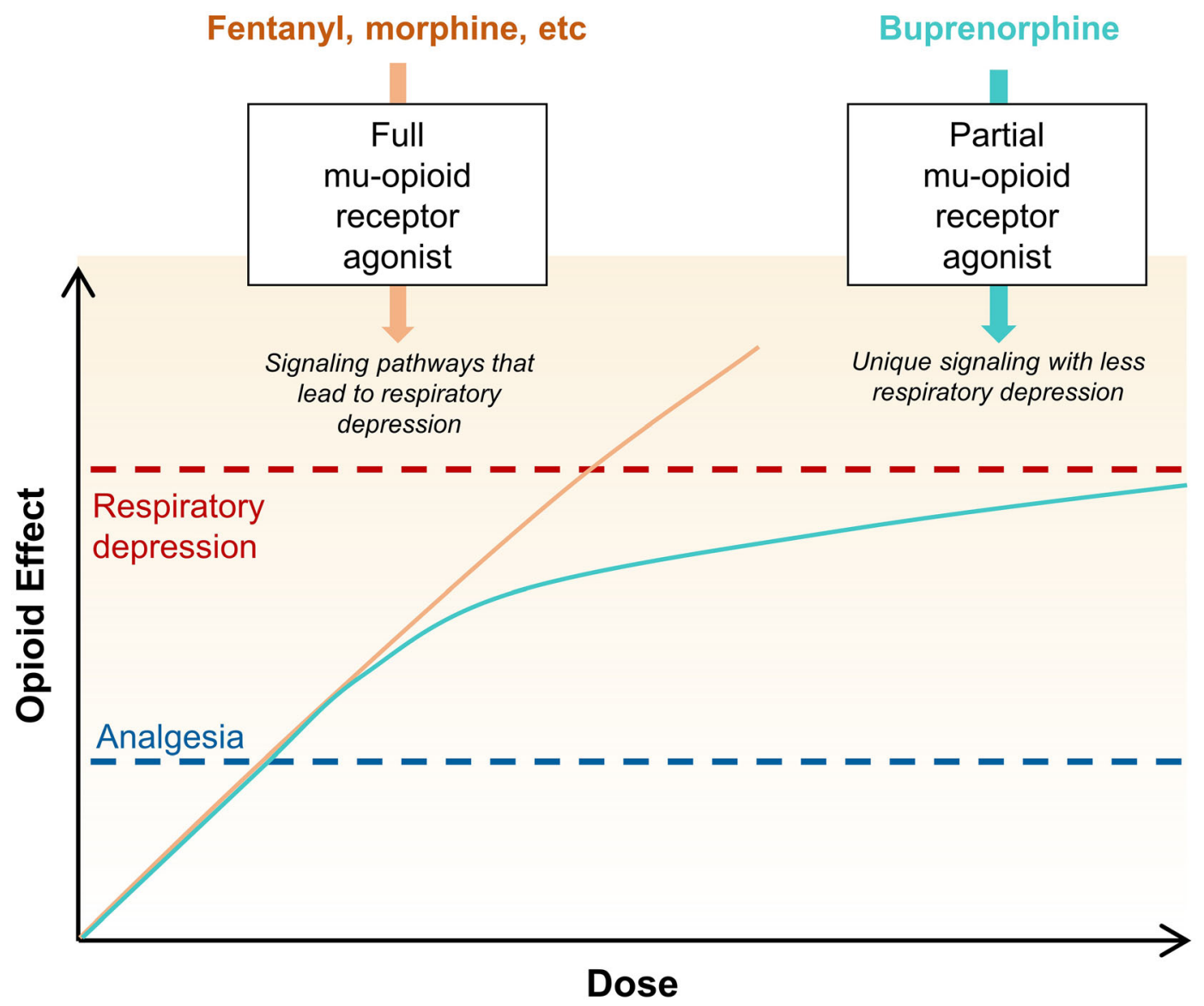

Fig. 8 Biased signaling: full vs partial mu-opioid receptor agonists. Buprenorphine has less intrinsic activity compared with full mu-opioid receptor agonists, which

must take caution when prescribing agents that can collectively enhance the potential for serious adverse events caused by CNS depressants [92].

In addition to sedative herbal supplements and antihistamines, the concomitant use of prescription analgesics with other drug classes such as gabapentinoids can also lead to increased CNS depression [82, 93]. The prescription of the gabapentinoid drugs gabapentin and pregabalin has recently increased because physicians and patients are seeking opioid alternatives for pain relief during the opioid crisis; however, gabapentinoids are often being co-prescribed with CNS depressants, such as opioids, thereby increasing the risk of lifethreatening and fatal respiratory depression $[93,94]$. The increased risk of adverse events translates to downstream signaling events that lead to effective analgesia but a decreased risk of respiratory depression

with concomitant use of CNS depressants and other medications and supplements must be considered prior to the prescription or recommendation of multiple agents.

\section{Assessment and Risks}

To promote patient safety, it is important that clinicians have a deep understanding of respiration as a whole, and how various pharmaceutical and recreational agents can impact each step of the process to cause respiratory depression. If a patient presents with chronic pain and opioid treatment is under consideration, a risk-benefit analysis should be performed, including the assessment of factors that influence respiration. Medical history should be 
carefully reviewed to identify conditions known to increase the risk of respiratory depression.

Stroke, encephalitis, and brainstem diseases decrease central respiratory drive and minute ventilation, thereby limiting respiratory function [45]. Primary spinal cord/lower motor neuron and muscle disorders, thoracic cage disorders, and metabolic disorders can decrease respiratory neuromuscular and thoracic cage function and lead to respiratory depression [45]. In addition, gas exchange abnormalities, such as pulmonary embolism and vascular disease, chronic obstructive pulmonary disease, fever, metabolic acidosis, and upper airway disorders, can decrease ventilation [45]. Congestive heart failure or chronic liver and kidney diseases may make some patients (i.e., the elderly) more sensitive to certain medications because of inadequate clearance or metabolism by the liver or kidney. This can cause fluid retention, which ultimately impairs diaphragm function and lung volume/reserve [95]. These and other underlying factors must be considered prior to prescribing CNS depressants, as they can cause synergistic depression of a patient's respiratory function.

Assessment of sleep disturbances is a key metric for evaluating patient risk as well as for monitoring opioid therapy [96]. During an exam, high blood pressure, body mass index $(>28)$, age $(\geq 50)$, neck circumference $\left(>17^{\prime \prime}\right.$ for men; $>16^{\prime \prime}$ for women), and sex (male) should be taken into account, as these factors may indicate greater risk of moderate to severe obstructive sleep apnea (OSA) [96-98]. A history of snoring, tiredness, and obstruction symptoms are also indicative of OSA [96-98]. Referral to a sleep specialist may be appropriate for some patients so that OSA can be diagnosed and treated or the response to opioid therapy can be gauged $[99,100]$. If a patient is receiving automatic positive airway pressure, the pressure can be interrogated to determine appropriate settings, but the optimization of sleep-related breathing therapies should be done in conjunction with a sleep specialist [100].

If sleep-related breathing is not an issue, incentive spirometry can be performed at home as a preventative measure to increase functional residual capacity. $\mathrm{O}_{2}$ saturation can be measured independently using arterial blood tests or as a noninvasive measurement of the percentage of saturated hemoglobin in the capillary bed using co-oximetry with a pulse oximeter [101]. Preference may also be to utilize the 6-min walk test, an exercise test that can be predictive of underlying lung issues [102].

If a patient is taking multiple medications, referral to a pain specialist may also be considered to optimize the use of multimodal agents without increasing the risk of respiratory depression [100, 103]. Prescribing CNS depressant medications should be a collaborative decision made by the multidisciplinary team responsible for a patient with chronic pain, including having full awareness of potential side effects, access to antidotes, and ensuring proper patient education regarding the administration and storage of medications [100]. In regard to the prescription of opioids, medication selection of atypical opioids (buprenorphine, tramadol, tapentadol) versus full muopioid receptor agonists (e.g., morphine, fentanyl, oxycodone) may limit adverse events, especially in terms of respiratory depression [1]; however, buprenorphine is unique in that it has a ceiling effect on respiratory depression but not on analgesia $[1,67,70]$. In humans, intravenous (IV) administration of fentanyl has been shown to suppress minute ventilation in a dose-dependent manner, whereas suppression of minute ventilation with IV administration of buprenorphine plateaued as the dose increased [67]. For this reason, many clinicians feel buprenorphine may be better tolerated than conventional full mu-opioid receptor agonists for the treatment of chronic pain [1].

\section{CONCLUSION}

Patients with chronic pain are often exposed to one or more pharmaceutical or recreational agents that impact respiration. Respiratory drive is controlled by the activity of a network of neurons within the brainstem. Respiration is influenced by peripheral and central chemoreceptor input (supplies information regarding arterial $\mathrm{pH}$ and $\mathrm{O}_{2}$ and $\mathrm{CO}_{2}$ levels) and mechanoreceptor input (provides information 
about the mechanical status of the lungs and chest). These processes work in synchrony to ensure appropriate ventilation by the lungs via signaling to the primary muscles of respiration to initiate the exchange of $\mathrm{CO}_{2}$ for $\mathrm{O}_{2}$. When one or more steps in respiration are suppressed, life-threatening respiratory depression can occur. Certain CNS depressant agents used alone or concomitantly (e.g., benzodiazepines, barbiturates, $\mathrm{Z}$ drugs, opioids, and ethanol) are well known to cause respiratory depression. Of note, opioid-induced respiratory depression has triggered a serious national health crisis, which may be mitigated through the prescription of medications less likely to impact respiratory drive, such as buprenorphine. Proper risk-benefit assessments, collaboration with a multidisciplinary team, medication selection, and patient education can aid in limiting the incidence of respiratory depression induced by pharmacologic agents or recreational substances. Thus, prior to prescribing certain medications, the risk of respiratory depression should be considered and precautions should be taken to reduce adverse outcomes, including death.

\section{ACKNOWLEDGEMENTS}

Funding. This article and the Rapid Service Fee were funded by BioDelivery Sciences International, Inc.

Medical Writing and Editorial Assistance. The authors thank Jessica Brunquell, PhD, of MedLogix Communications, LLC, Itasca, IL, for medical writing and editorial support, which was funded by BioDelivery Sciences International, Inc.

Authorship. All named authors meet the International Committee of Medical Journal Editors (ICMJE) criteria for authorship for this article, take responsibility for the integrity of the work as a whole, and have given their approval for this version to be published.
Disclosures. Lynn R. Webster has received consultation, advisory board, and travel fees from Charleston Laboratories, Depomed, Egalet, Insys Therapeutics, Mallinckrodt Pharmaceuticals, Pfizer, Teva, and Trevena; consultation and travel fees from Alcobra, Bonti, Daiichi Sankyo, Elysium Health, Indivior, KemPharm, Pain Therapeutics, Pernix Therapeutics, and Shionogi; advisory board and travel fees from BioDelivery Sciences International, Inc., Ensysce Biosciences, and Inspirion Pharmaceuticals; travel fees from Cara Therapeutics; and consultation fees from Jefferies, Merck, Trevi Therapeutics, Vallon Pharmaceuticals, and Vector Pharma. Suzanne Karan is a co-investigator for SAFeR which is sponsored by the ResMed Foundation.

Compliance with Ethics Guidelines. This article is based on previously conducted studies and does not contain any studies with human participants or animals performed by any of the authors.

Data Availability. Data sharing is not applicable to this article, as no datasets were generated or analyzed during the current study.

Open Access. This article is licensed under a Creative Commons Attribution-NonCommercial 4.0 International License, which permits any non-commercial use, sharing, adaptation, distribution and reproduction in any medium or format, as long as you give appropriate credit to the original author(s) and the source, provide a link to the Creative Commons licence, and indicate if changes were made. The images or other third party material in this article are included in the article's Creative Commons licence, unless indicated otherwise in a credit line to the material. If material is not included in the article's Creative Commons licence and your intended use is not permitted by statutory regulation or exceeds the permitted use, you will need to obtain permission directly from the copyright holder. To view a copy of this licence, visit http://creativecommons.org/licenses/by$\mathrm{nc} / 4.0 /$. 


\section{REFERENCES}

1. Rosenquist R. Use of opioids in the management of chronic non-cancer pain. In: Aaronson M, Fishman S, Crowley M, editors. UpToDate. Waltham: UptoDate; 2020.

2. Dahlhamer J, Lucas J, Zelaya C, et al. Prevalence of chronic pain and high-impact chronic pain among adults-United States, 2016. MMWR Morb Mortal Wkly Rep. 2018;67(36):1001-6.

3. National Center for Complementary and Integrative Health. Chronic pain: in depth. https://www. nccih.nih.gov/health/chronic-pain-in-depth. Accessed July 9, 2020.

4. Dahan A, van der Schrier R, Smith T, Aarts L, van Velzen M, Niesters M. Averting opioid-induced respiratory depression without affecting analgesia. Anesthesiology. 2018;128(5):1027-37.

5. Volkow ND, McLellan AT. Opioid abuse in chronic pain-misconceptions and mitigation strategies. N Engl J Med. 2016;374(13):1253-63.

6. Centers for Disease Control. Prescription opioid overdose data. Wide-ranging online data for epidemiologic research (WONDER); 2016. https:// www.cdc.gov/drugoverdose/data/prescribing/over view.html. Accessed May 22, 2020.

7. Jonkman AH, de Vries HJ, Heunks LMA. Physiology of the respiratory drive in ICU patients: implications for diagnosis and treatment. Crit Care. 2020;24(1):104.

8. Stoppler M. Medical definition of respiratory depression; 2017. https://www.medicinenet.com/ script/main/art.asp?articlekey=201755. Accessed Mar 19, 2020.

9. Montandon G, Slutsky AS. Solving the opioid crisis: respiratory depression by opioids as critical end point. Chest. 2019;156(4):653-8.

10. Schiller EY, Mechanic OJ. Opioid overdose. Treasure Island: StatPearls; 2020.

11. Brinkman JE, Sharma S. Physiology, respiratory drive. Treasure Island: StatPearls; 2020.

12. Cloutier M. Control of respiration. In: Respiratory physiology. 2nd ed. Amsterdam: Elsevier; 2018.

13. West JB, Luks AM. West's respiratory physiology: the essentials. 10th ed. Philadelphia: Wolters Kluwer; 2016.
14. Johnson D. Disorders of ventilatory control. In: Manaker S, Hollingsworth H, Eichler A, editors. UpToDate. Waltham: UptoDate; 2020.

15. Alheid GF, McCrimmon DR. The chemical neuroanatomy of breathing. Respir Physiol Neurobiol. 2008;164(1-2):3-11.

16. Dubois M, Chenivesse C, Raux M, et al. Neurophysiological evidence for a cortical contribution to the wakefulness-related drive to breathe explaining hypocapnia-resistant ventilation in humans. J Neurosci. 2016;36(41):10673-82.

17. Fink BR. Influence of cerebral activity in wakefulness on regulation of breathing. J Appl Physiol. 1961;16:15-20.

18. Lumb, A. Control of breathing. In: Nunn's applied respiratory physiology. 8th ed. Amsterdam: Elsevier; 2016.

19. Bolser DC, Pitts TE, Davenport PW, Morris KF. Role of the dorsal medulla in the neurogenesis of airway protection. Pulm Pharmacol Ther. 2015;35:105-10.

20. Pagliardini S, Janczewski WA, Tan W, Dickson CT, Deisseroth K, Feldman JL. Active expiration induced by excitation of ventral medulla in adult anesthetized rats. J Neurosci. 2011;31(8):2895-905.

21. Moini J. Respiratory system. In: Moini J, editor. Anatomy and physiology for healthcare professionals. 3rd ed. Burlington: Jones and Bartlett Learning; 2020. p. 538-570.

22. Bonham AC. Neurotransmitters in the CNS control of breathing. Respir Physiol. 1995;101(3):219-30.

23. Dutschmann M, Dick TE. Pontine mechanisms of respiratory control. Compr Physiol. 2012;2(4): 2443-699.

24. Daly M. Hypoventilation. In: Silverstein D, Ryan M, Hopper K, editors. Small animal critical care medicine. 2nd ed. Philadelphia: Saunders; 2014. p. 86-92.

25. Horn EM, Waldrop TG. Suprapontine control of respiration. Respir Physiol. 1998;114(3):201-11.

26. Betts J, Kelly A, Wise J. The process of breathing. In: Anatomy and physiology. Houston: OpenStax; 2013.

27. Gourine A, Spyer K. Autonomic nervous system: central respiratory control. Encyclopedia of neuroscience; 2009. p. 883-890.

28. Elliot, D. Human respiratory system. Published February 13, 2020. https://www.britannica.com/ 
science/human-respiratory-system. Accessed Mar 25,2020 .

29. Vadhan J, Tadi P. Physiology, Herring Breuer reflex. Treasure Island: StatPearls; 2020.

30. Schwartzstein R. Dyspnea. In: Kasper D, Fauci A, Hauser S, editors. Harrison's principles of internal medicine. 19th ed. New York: McGraw-Hill; 2015.

31. Johnson D. Control of ventilation. In: Flaherty K, Manaker S, Finlay G, editors. UpToDate. Waltham: UptoDate; 2020.

32. Ward DS, Dahan A, Teppema LJ. Pharmacology and pathophysiology of the control of breathing. Boca Raton: Taylor and Francis; 2005.

33. Guyenet PG, Stornetta RL, Bayliss DA. Retrotrapezoid nucleus and central chemoreception. J Physiol. 2008;586(8):2043-8.

34. Molkov YI, Bacak BJ, Dick TE, Rybak IA. Control of breathing by interacting pontine and pulmonary feedback loops. Front Neural Circuits. 2013;7:16.

35. Katz E. Disorders of central respiratory control during sleep in children. In: Therapy in sleep medicine. 1st ed. Philadelphia: Elsevier; 2011.

36. Tamul P, Ault M. Respiratory function in anesthesia. In: Barash PG, Cullen BF, Stoelting RK, Cahalan MK, Stock MC, Ortega R, editors. Clinical anesthesia. 8th ed. Philadelphia: Lippincott Williams and Wilkins; 2017.

37. Strohl KP, Butler JP, Malhotra A. Mechanical properties of the upper airway. Compr Physiol. 2012;2(3):1853-72.

38. Schwartz AR, Smith PL. CrossTalk proposal: the human upper airway does behave like a Starling resistor during sleep. J Physiol. 2013;591(9): 2229-32.

39. Series F, Cormier Y, Desmeules M. Influence of passive changes of lung volume on upper airways. J Appl Physiol. 1990;68(5):2159-64.

40. Betts J, Kelly A, Wise J. Modifications in respiratory functions. In: Anatomy and physiology. Houston: OpenStax; 2013.

41. Hall JE. Respiration. In: Guyton and Hall textbook of medical physiology. 13th ed. Philadelphia: Elsevier; 2015. p. 497-557.

42. Kaynar A. Respiratory failure. Updated July 25, 2018. https://emedicine.medscape.com/article/ 167981. Accessed Mar 26, 2020.
43. Hallett S, Toro F, Ashurst JV. Physiology, tidal volume. Treasure Island: StatPearls; 2020.

44. Hirshman CA, McCullough RE, Weil JV. Normal values for hypoxic and hypercapnic ventilatory drives in man. J Appl Physiol. 1975;38(6):1095-8.

45. Feller-Kopman DJ, Schwartzstein RM. Mechanisms, causes, and effects of hypercapnia. In: Stoller J, Finlay G, editors. UpToDate. Waltham: UptoDate; 2020.

46. Benner A, Sharma S. Physiology, carbon dioxide response curve. Treasure Island: StatPearls; 2020.

47. Dolinak D. Opioid toxicity. Acad Forensic Pathol. 2017;7(1):19-35.

48. Boom M, Niesters M, Sarton E, Aarts L, Smith TW, Dahan A. Non-analgesic effects of opioids: opioidinduced respiratory depression. Curr Pharm Des. 2012;18(37):5994-6004.

49. Vieweg WV, Lipps WF, Fernandez A. Opioids and methadone equivalents for clinicians. Prim Care Companion J Clin Psychiatry. 2005;7(3):86-8.

50. Pattinson KT. Opioids and the control of respiration. Br J Anaesth. 2008;100(6):747-58.

51. Pattinson KT, Governo RJ, MacIntosh BJ, et al. Opioids depress cortical centers responsible for the volitional control of respiration. J Neurosci. 2009;29(25):8177-86.

52. Fayyaz J. Hypoventilation syndromes; 2018. https:// emedicine.medscape.com/article/304381-print. Accessed May 19, 2020.

53. Huizen J. What to know about respiratory depression; 2017. https://www.medicalnewstoday.com/ articles/319030. Accessed May 26, 2020.

54. Suddock JT, Cain MD. Barbiturate toxicity. Treasure Island: StatPearls; 2020.

55. Tobias JD, Leder M. Procedural sedation: a review of sedative agents, monitoring, and management of complications. Saudi J Anaesth. 2011;5(4):395-410.

56. Bonnet $\mathrm{MH}$, Arand DL. Behavioral and pharmacologic therapies for chronic insomnia in adults. In: Benca R, Eichler A, editors. UpToDate. Waltham: UptoDate; 2020.

57. Vozoris NT. Do benzodiazepines contribute to respiratory problems? Expert Rev Respir Med. 2014;8(6):661-3.

58. Kang M, Ghassemzadeh S. Benzodiazepine toxicity. Treasure Island: StatPearls; 2020. 
59. Beaupre A, Soucy R, Phillips R, Bourgouin J. Respiratory center output following zopiclone or diazepam administration in patients with pulmonary disease. Respiration. 1988;54(4):235-40.

60. Chung WS, Lai CY, Lin CL, Kao CH. Adverse respiratory events associated with hypnotics use in patients of chronic obstructive pulmonary disease: a population-based case-control study. Medicine (Baltimore). 2015;94(27):e1110.

61. Saraswat V. Effects of anaesthesia techniques and drugs on pulmonary function. Indian J Anaesth. 2015;59(9):557-64.

62. LaHood A, Kok S. Ethanol toxicity. Treasure Island: StatPearls; 2020.

63. MedlinePlus. Secobarbital. https://medlineplus.gov/ druginfo/meds/a682386.html. Accessed Aug 24, 2020.

64. Kennedy KM, O'Riordan J. Prescribing benzodiazepines in general practice. $\mathrm{Br} \mathrm{J}$ Gen Pract. 2019;69(680):152-3.

65. Webster LR, Choi Y, Desai H, Webster L, Grant BJ. Sleep-disordered breathing and chronic opioid therapy. Pain Med. 2008;9(4):425-32.

66. Carberry JC, Fisher LP, Grunstein RR, et al. Role of common hypnotics on the phenotypic causes of obstructive sleep apnoea: paradoxical effects of zolpidem. Eur Respir J. 2017;50(6):1701344.

67. Dahan A, Yassen A, Bijl H, et al. Comparison of the respiratory effects of intravenous buprenorphine and fentanyl in humans and rats. Br J Anaesth. 2005;94(6):825-34.

68. Emery MA, Eitan S. Members of the same pharmacological family are not alike: different opioids, different consequences, hope for the opioid crisis? Prog Neuropsychopharmacol Biol Psychiatry. 2019;92:428-49.

69. United States Department of Health and Human Services. Report on pain management best practices: updates, gaps, inconsistencies, and recommendations. https://www.hhs.gov/ash/advisorycommittees/pain/reports/index.html. Updated December 16, 2019. Accessed May 26, 2020.

70. Dahan A, Yassen A, Romberg R, et al. Buprenorphine induces ceiling in respiratory depression but not in analgesia. Br J Anaesth. 2006;96(5):627-32.

71. van der Schrier R, Roozekrans M, van Velzen M, Dahan A, Niesters M. Opioid-induced respiratory depression: reversal by non-opioid drugs. F1000Prime Rep. 2014;6:79.
72. Durotram XR. Prescribing information. Chatswood: iNova Pharmaceuticals; 2019.

73. Nucynta ER. Prescribing information. Stoughton: Collegium Pharmaceutical Inc.; 2019.

74. Gudin J, Fudin J. A narrative pharmacological review of buprenorphine: a unique opioid for the treatment of chronic pain. Pain Ther. 2020;9(1): $41-544$.

75. Pedersen MF, Wrobel TM, Marcher-Rorsted E, et al. Biased agonism of clinically approved mu-opioid receptor agonists and TRV130 is not controlled by binding and signaling kinetics. Neuropharmacology. 2020;166:107718.

76. Davis MP, Pasternak G, Behm B. Treating chronic pain: an overview of clinical studies centered on the buprenorphine option. Drugs. 2018;78(12): 1211-28.

77. Raffa RB, Haidery M, Huang HM, et al. The clinical analgesic efficacy of buprenorphine. J Clin Pharm Ther. 2014;39(6):577-83.

78. McPherson J, Rivero G, Baptist M, et al. mu-Opioid receptors: correlation of agonist efficacy for signalling with ability to activate internalization. Mol Pharmacol. 2010;78(4):756-66.

79. Corder G, Castro DC, Bruchas MR, Scherrer G. Endogenous and exogenous opioids in pain. Annu Rev Neurosci. 2018;41:453-73.

80. Tori ME, Larochelle MR, Naimi TS. Alcohol or benzodiazepine co-involvement with opioid overdose deaths in the United States, 1999-2017. JAMA Netw Open. 2020;3(4):e202361.

81. Alexander CM, Seifert HA, Blouin RT, Conard PF, Gross JB. Diphenhydramine enhances the interaction of hypercapnic and hypoxic ventilatory drive. Anesthesiology. 1994;80(4):789-95.

82. Abebe W. Herbal medication: potential for adverse interactions with analgesic drugs. J Clin Pharm Ther. 2002;27(6):391-401.

83. Bilia AR, Gallon S, Vincieri FF. Kava-kava and anxiety: growing knowledge about the efficacy and safety. Life Sci. 2002;70(22):2581-97.

84. Kapalka G. Anxiety disorders. In: Nutritional and herbal therapies for children and adolescents a handbook for mental health clinicians practical resources for the mental health professional. San Diego: Academic; 2010. p. 219-58.

85. Wadehra S. Is kratom a viable alternative to opioids? https://www.practicalpainmanagement.com/ 
patient/treatments/alternative/kratom-viablealternative-opioids. Accessed June 15, 2020.

86. Overbeek DL, Abraham J, Munzer BW. Kratom (mitragynine) ingestion requiring naloxone reversal. Clin Pract Cases Emerg Med. 2019;3(1):24-6.

87. Hays SR. Inhalation anesthetic agents: clinical effects and uses. In: Joshi G, Nussmeier N, editors. UpToDate. Waltham: UptoDate; 2020.

88. van der Schrier R, Roozekrans M, Olofsen E, et al. Influence of ethanol on oxycodone-induced respiratory depression: a dose-escalating study in young and elderly individuals. Anesthesiology. 2017;126(3):534-42.

89. Fudin J. The perfect storm: opioid risks and "The Holy Trinity". https://www.pharmacytimes.com/ contributor/jeffrey-fudin/2014/09/the-perfectstorm-opioid-risks-and-the-holy-trinity. Accessed June 15, 2020.

90. Horsfall JT, Sprague JE. The pharmacology and toxicology of the 'Holy Trinity'. Basic Clin Pharmacol Toxicol. 2017;120(2):115-9.

91. Substance Abuse and Mental Health Services Administration, Center for Behavioral Health Statistics and Quality. December 18, 2014. The DAWN report: benzodiazepines in combination with opioid pain relievers or alcohol: greater risk of more serious ED visit outcomes. Rockville: SAMHSA.

92. Anwari JS, Iqbal S. Antihistamines and potentiation of opioid induced sedation and respiratory depression. Anaesthesia. 2003;58(5):494-5.

93. Goodman CW, Brett AS. Gabapentinoids for pain: potential unintended consequences. Am Fam Physician. 2019;100(11):672-5.

94. US Food and Drug Administration. FDA warns about serious breathing problems with seizure and nerve pain medicines gabapentin (Neurontin,
Gralise, Horizant) and pregabalin (Lyrica, Lyrica CR). https://www.fda.gov/drugs/drug-safety-andavailability/fda-warns-about-serious-breathingproblems-seizure-and-nerve-pain-medicinesgabapentin-neurontin. Accessed June 17, 2020.

95. Hughes SG. Prescribing for the elderly patient: why do we need to exercise caution? Br J Clin Pharmacol. 1998;46(6):531-3.

96. Oregon Pain Guidance. Opioid prescribing guidelines. https://www.careoregon.org/docs/defaultsource/providers/manuals-and-formulary/opioidprescribers-guidelines.pdf?sfvrsn=2672e9e6_0. Accessed July 10, 2020.

97. Chung F, Abdullah HR, Liao P. STOP-Bang questionnaire: a practical approach to screen for obstructive sleep apnea. Chest. 2016;149(3):631-8.

98. Chung F, Yegneswaran B, Liao P, et al. STOP questionnaire: a tool to screen patients for obstructive sleep apnea. Anesthesiology. 2008;108(5):812-21.

99. Collop N. Home sleep apnea testing for obstructive sleep apnea in adults. In: Harding S, Finlay G, editors. UpToDate. Waltham: UptoDate; 2020.

100. Rosen IM, Aurora RN, Kirsch DB, et al. Chronic opioid therapy and sleep: an American Academy of Sleep Medicine position statement. J Clin Sleep Med. 2019;15(11):1671-3.

101. Theodore AC. Measures of oxygenation and mechanisms of hypoxemia. In: Parsons P, Finlay G, editors. UpToDate. Waltham: UptoDate; 2020.

102. Agrawal MB, Awad NT. Correlation between six minute walk test and spirometry in chronic pulmonary disease. J Clin Diagn Res. 2015;9(8): OC01-4.

103. Dowell D, Haegerich TM, Chou R. CDC guideline for prescribing opioids for chronic pain-United States, 2016. MMWR Recomm Rep. 2016;65(1): $1-49$. 